\title{
Clinical Results of 40 Consecutive Basal Thumb Prostheses and No CRPS Type I After Vitamin C Prophylaxis
}

\author{
Paul E. Zollinger ${ }^{*}, 1$, Halil Ünal ${ }^{1}$, Maarten L. Ellis ${ }^{1}$ and Wim E. Tuinebreijer ${ }^{2}$ \\ ${ }^{I}$ Department of Orthopaedic Surgery, Ziekenhuis Rivierenland, Pres. Kennedylaan 1, 4002 WP Tiel, The Netherlands \\ ${ }^{2}$ Relweg 59, 1949 EC Wijk aan Zee, The Netherlands
}

\begin{abstract}
Complex regional pain syndrome (CRPS) type I may occur as complication after any type of surgery for basal joint arthritis of the thumb. We investigated prospectively in an ongoing study our results after a fully standardized treatment with a total joint prosthesis under vitamin $\mathrm{C}$ prophylaxis.

Patients with trapeziometacarpal arthritis stage II or III according to Dell, and no benefit from conservative treatment, were selected to undergo joint replacement with a semi-constrained hydroxyapatite coated prosthesis.

First web opening and visual analogue scale (VAS) scores for pain, activities of daily living (ADL) and satisfaction were taken pre and postoperatively. Vitamin C $500 \mathrm{mg}$ daily was started two days prior to surgery during 50 days as prevention for CRPS. Post-operative treatment was functional.

We performed 40 implantations for trapeziometacarpal arthritis in 34 patients (mean age 60.8 years; 27 females, 7 males) with a mean follow-up of 44 months. Operations were performed in day care under regional (or general) anesthesia.

First web opening increased with 15.4 degrees and there was a significant improvement for pain, ADL and satisfaction as well $(p=0.000)$. Patient satisfaction was strongly associated with the amount of pain reduction. According to the Veldman and IASP criteria, there were no cases of CRPS.

The overall complication rate for this procedure is high. Literature reports 5 cases of CRPS after 38 operations with the same implant (13\%). We advise vitamin C as prophylaxis against CRPS in trapeziometacarpal joint replacement.
\end{abstract}

Keywords: Trapeziometacarpal arthritis, joint replacement, reflex sympathetic dystrophy, ascorbic acid, CMC I prosthesis, complex regional pain syndrome.

\section{INTRODUCTION}

Basal joint arthritis of the thumb is a common site for arthritis in the hand and the prevalence is highest in women [1]. Different classifications have been described in the past $[2,3]$. The classification according to Dell combines radiological evaluation with clinical features and has our preference.

Basal joint arthritis of the thumb is also called arthritis of the carpometacarpal (CMC) joint of the thumb or first carpometacarpal joint (CMC I) or trapeziometacarpal (TM) osteoarthritis.

Most patients with trapeziometacarpal arthritis are treated conservatively. These treatments differ in efficacy and may be applied as single treatment or in combination with each other. Conservative options are drug therapy, splinting or bracing, injection therapy and physical therapy. If these therapies fail, or if the process of degeneration and arthritis continues, surgical intervention might be a next option.

*Address correspondence to this author at the Department of Orthopaedics, Ziekenhuis Rivierenland Tiel, P.O. Box 6024, 4000 HA Tiel, The Netherlands; Tel: +31344674217; Fax: +31344632903;

E-mail: PE.Zollinger@tiscali.nl
Different surgical solutions are suggested in literature. The most common procedures are resection-arthroplasty, partial trapeziectomy, interposition arthroplasty [4], spacer interposition, fusion or arthrodesis [5] and prosthetic joint replacement [6]. These surgical interventions are not without the risk of the occurrence of a variety of complications. After any type of surgery for basal joint arthritis of the thumb complex regional pain syndrome (CRPS) type I may occur as a complication [7]. This is a debilitating acute pain syndrome, which could develop into a chronic disability. As there is no real cure for CRPS, one should emphasize on the prevention of what was formerly known as reflex sympathetic dystrophy (RSD). Our study group and others have reported a beneficial effect of the prophylactic vitamin $\mathrm{C}$ administration on the occurrence of CRPS in wrist fractures [8-10].

Now we will report our ongoing prospective results after a fully standardized treatment with a joint prosthesis for trapeziometacarpal arthritis under vitamin $\mathrm{C}$ prophylaxis.

\section{MATERIALS AND METHODOLOGY}

\section{Methods}

Patients with trapeziometacarpal arthritis stage II or III according to Dell, and no benefit from conservative 
treatment, were selected to undergo joint replacement with a total joint prosthesis (Figs. 1, 2).

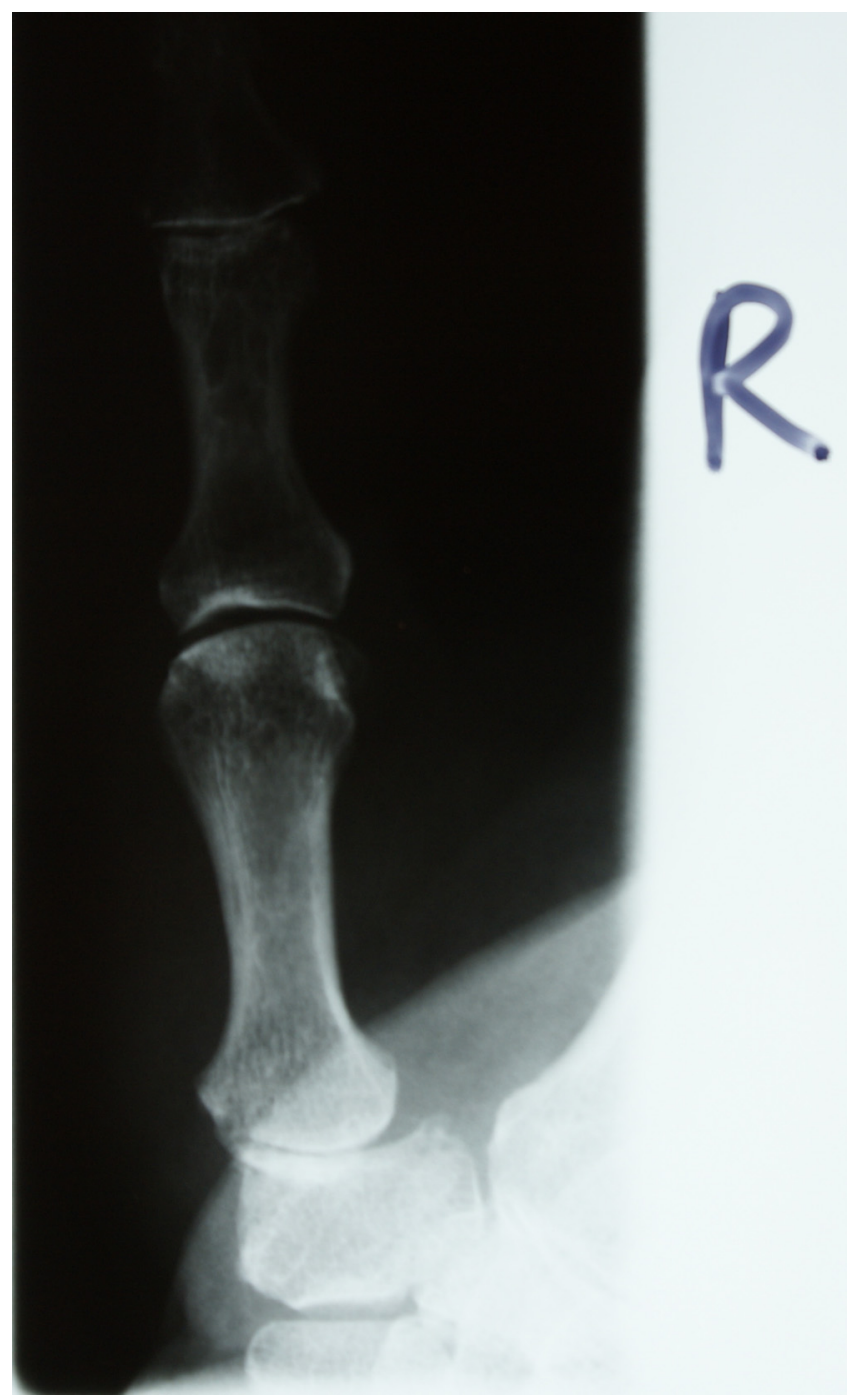

Fig. (1). Trapeziometacarpal arthritis stage II according to Dell.

The conservative treatment we applied consisted of oral medication (non-steroidal anti-inflammatory drugs), injections (corticosteroids), physical therapy (intrinsic thenar musculature strengthening), casting or bracing, alone or in a combination. Patients with a Dell stage I were not operated and for a Dell stage IV, to our opinion, a single prosthetic replacement is not the therapy of choice.

First web opening and visual analogue scale (VAS) scores for pain, activities of daily living (ADL) and satisfaction were taken pre- and postoperatively. In the score for pain, zero represents no pain and 10 means unbearable pain [11]. In the ADL and satisfaction scores, zero means the worst imaginable outcome and 10 the best imaginable result.

To prevent against complex regional pain syndrome type I (CRPS-I), the patients took $500 \mathrm{mg}$ ascorbic acid once daily two days before surgery during a period of 50 days, as was learned from two randomized clinical trials with distal radial fractures under vitamin $\mathrm{C}$ prophylaxis $[8,9]$.

The patients were allowed to choose their type of anesthesia; the choice was between plexus or general anesthesia. All patients were operated using a tourniquet through a dorsoradial approach by a single surgeon (first author), after administration of $1 \mathrm{~g}$ cefazolin intravenously half an hour pre-operatively.

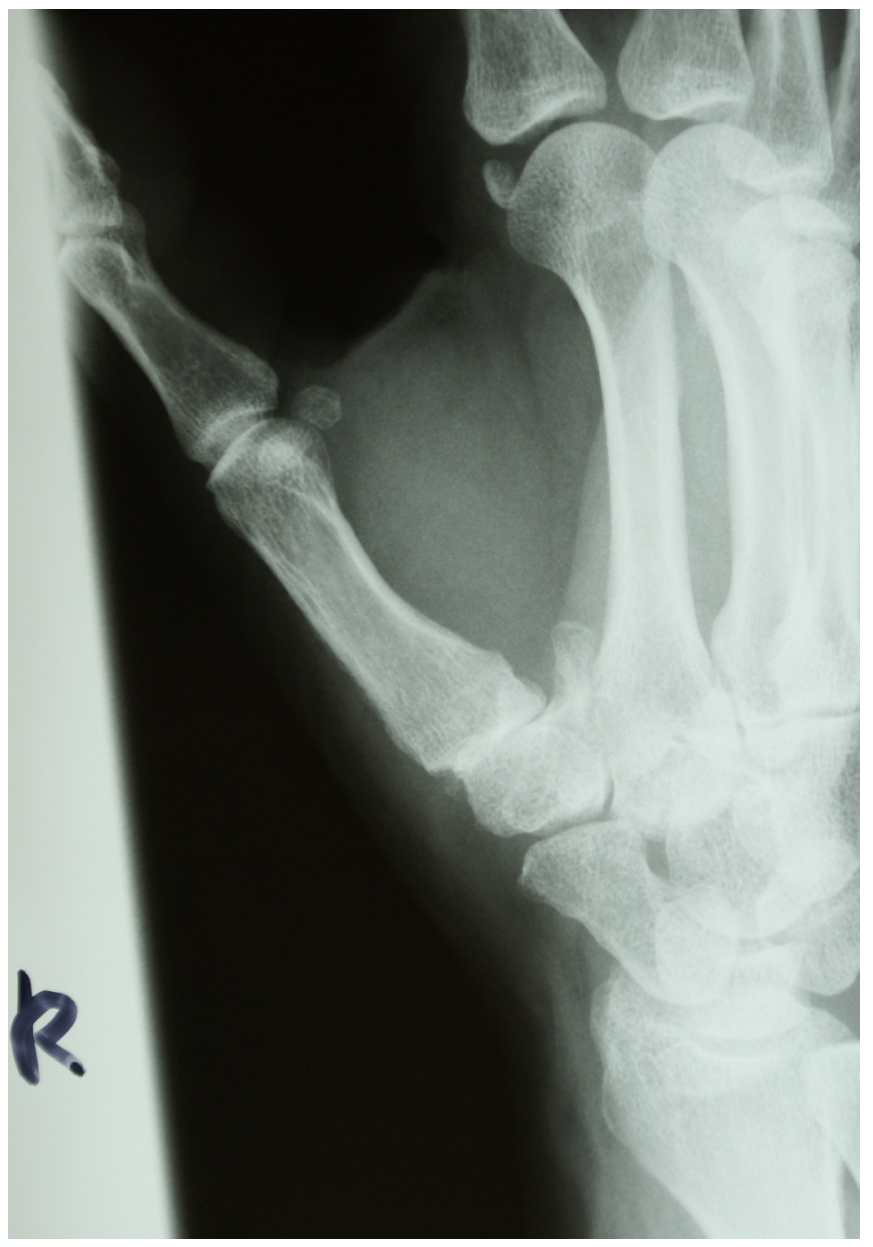

Fig. (2). Trapeziometacarpal arthritis stage III according to Dell.

In all cases a cementless total trapeziometacarpal semiconstrained joint prosthesis (Roseland prosthesis, DePuy International Ltd, Leeds, England) was used (Figs. 3, 4). This prosthesis is made of titanium alloy and has a partial hydroxyapatite coating proximal around the metacarpal stem and is fully hydroxyapatite coated around the trapezial cup for press-fit implantation [12]. The stem forms with the head a monoblock type. The cup has a fixed polyethylene insert.

The postoperative care was also standardized. In the first five postoperative days there was an immobilization in a bandage only. Thereafter the treatment was fully functional and the patients started active circumduction and opposition exercises. Passive immobilization was not allowed and physical therapy was started after 6 weeks, but only then when necessary.

Follow-up visits were planned after 5 days, and with VAS scores after 2 weeks, 6 weeks (with radiographic control; Fig. 3), 3 months, 6 months and 12 months (with Xray again; Fig. 4). Thereafter the controls were once yearly.

There is no golden standard for the diagnosis of complex regional pain syndrome type I. In the Netherlands the classification of Veldman et al. is favorable above the criteria of the International Association for the Study of Pain (IASP 1994) [13-15]. The reason for this is that the Veldman 
criteria are an empirically derived classification from a cohort of 829 patients. The IASP criteria are the consensus result from expert opinions, but unfortunately they lack specificity. In this article we used both for scientific reasons.

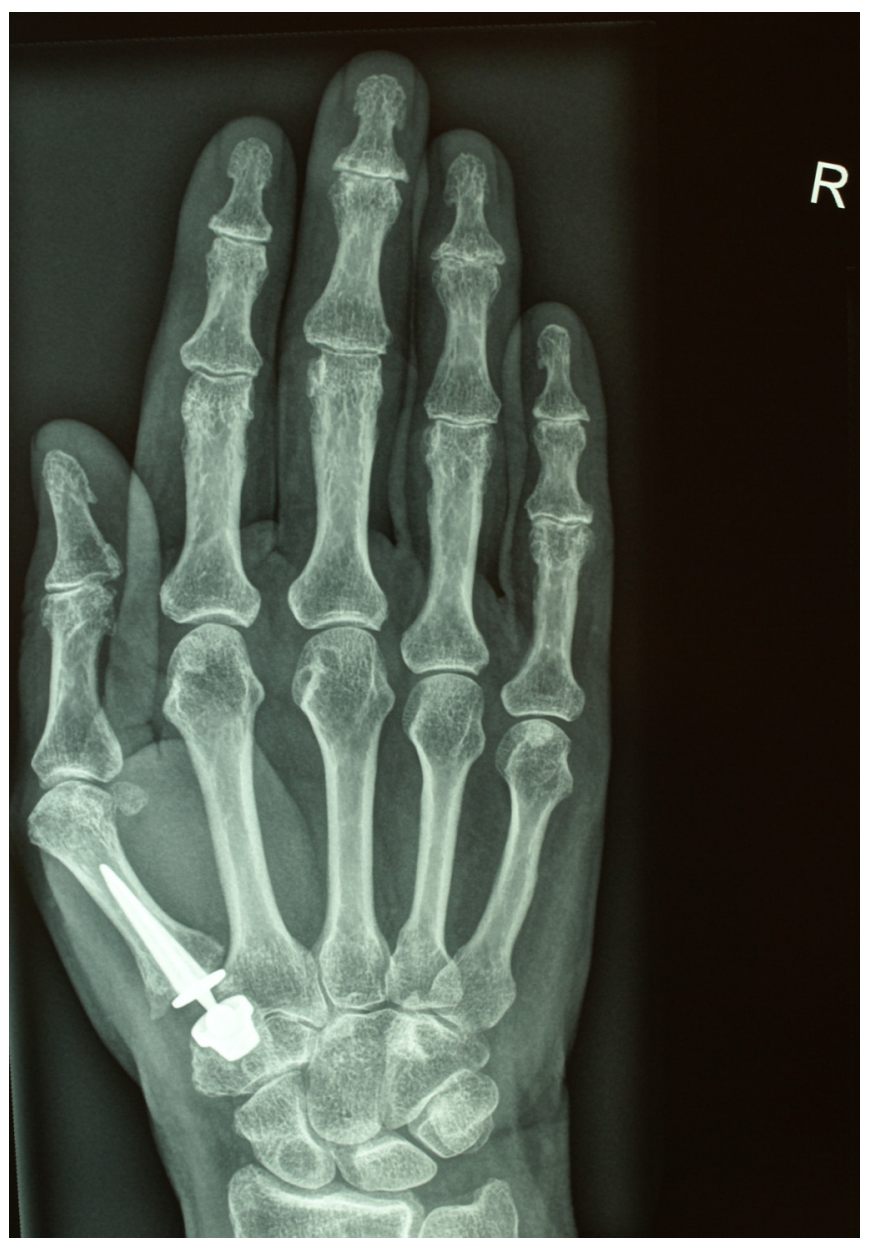

Fig. (3). The same patient as in Fig. (1); after implantation of a Roseland prosthesis (DePuy Int. Ltd., Leeds, England).

CRPS type I according to Veldman is diagnosed when four of the following five symptoms are present and occur or increase with activity:

1. unexplained diffuse pain;

2. difference in skin colour relative to the other hand;

3. diffuse oedema;

4. difference in skin temperature relative to the other hand;

5. limited active range of motion [13].

The original diagnostic criteria of the International Association for the Study of Pain (IASP) for CRPS-I are:

1. The presence of an initiating noxious event, or a cause of immobilization

2. Continuing pain, allodynia, or hyperalgesia with which the pain is disproportionate to any inciting event.

3. evidence at some time of edema, changes in skin blood flow, or abnormal sudomotor activity in the region of the pain.
4. This diagnosis is excluded by the existence of conditions that would otherwise account for the degree of pain and dysfunction (Note: Criteria 2-4 must be satisfied).

CRPS-II develops after a nerve injury [14].

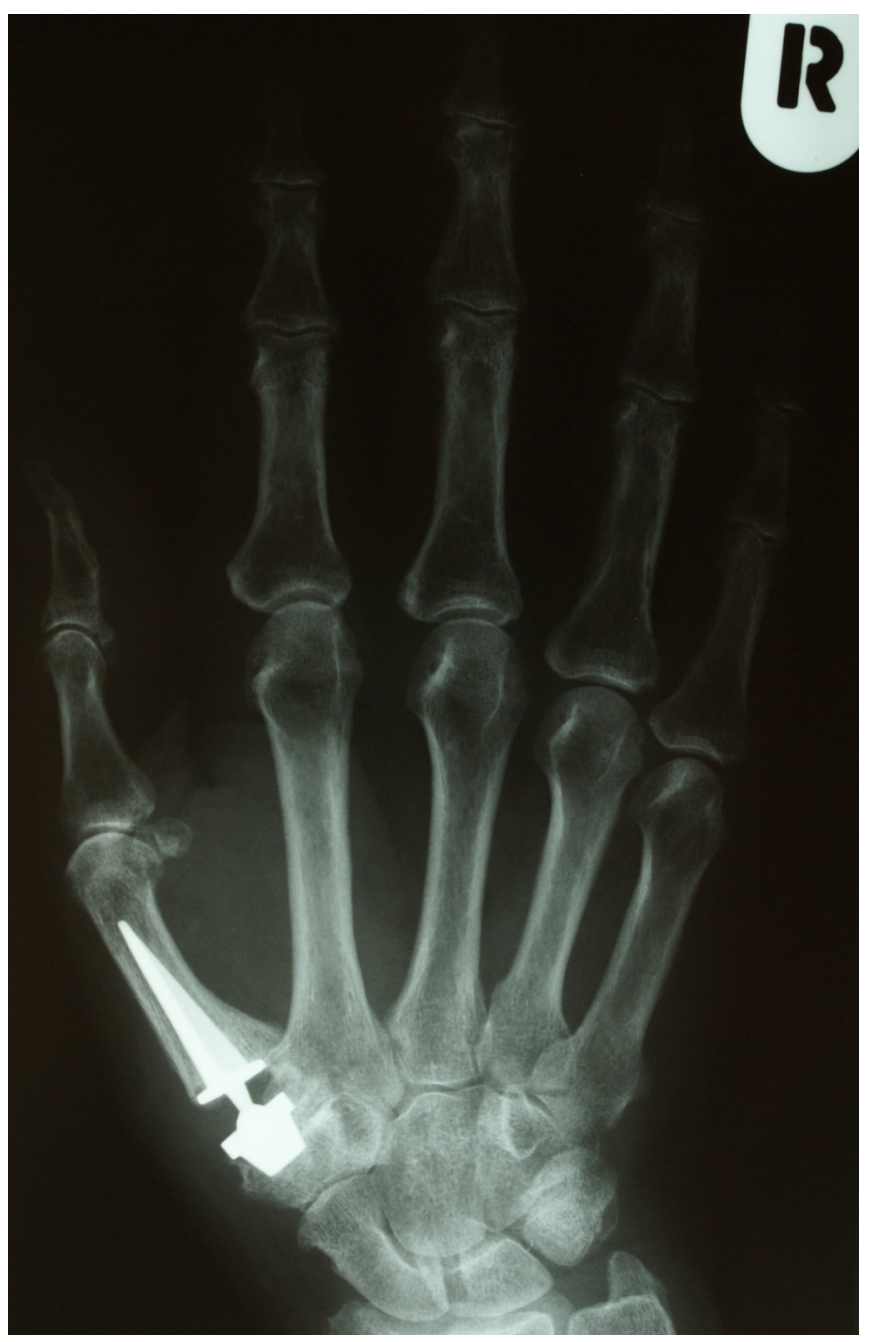

Fig. (4). The same patient as in Fig. (2); after implantation of a Roseland prosthesis (Depuy Int. Ltd., Leeds, England).

\section{Statistics}

The statistical analysis was performed with SPSS (version 15.0.1) software on a personal computer. The paired t-test, Wilcoxon signed rank test and the Mann-Whitney U test were used as applicable for univariate analysis.

The relationship between patient satisfaction and the other studied variables was estimated using multiple regression. Non-significant variables were removed one by one, removing the largest $\mathrm{p}$ value first, until all remaining variables in the model were significant.

\section{RESULTS}

We operated 40 hands in 34 patients. These 40 performed implantations for trapeziometacarpal arthritis were mainly under regional (or plexus) anesthesia and only 3 times under general anesthesia. Mean age of the operated patients was 60.8 years $(\mathrm{SD}=8.1)$. There were 27 females and 7 males. In these 34 patients, there were 24 hands with stage III osteoarthritis 
according to Dell and 15 hands with stage II osteoarthritis according to Dell [2]. One patient had a traumatic dislocation of the trapeziometacarpal joint after a fall from the stairs. She was also treated with total joint replacement and with a plaster cast for 6 weeks postoperatively [16].

The median duration of complaints was 45.7 months (SD $=39.2$ ).

The median time to surgery since the first complaints in patients with a Dell stage III was 48 months (interquartile range IQR $=36$ ). For patients with a Dell stage II it was 24 months $(\mathrm{IQR}=30)$. The $\mathrm{p}$-value for the difference of time to surgery was 0.09 .

First web opening increased with 15.4 degrees and there was a significant improvement for pain, ADL and satisfaction as well $(\mathrm{p}=0.000)$. Patient satisfaction was strongly associated with the amount of pain reduction (Spearman's rho 0.59) (Table 1).

Complications occurred in 6 of 40 surgical procedures (15\%), but there were no infections.

In four cases a revision had to be performed (10\%). Two times this was necessary because of a dislocation of the cup, and one because of a fracture of the trapezium.

A fourth revision was needed for an aseptic loosening of the cup after more than one year after the implantation. In these four cases a resection arthroplasty was carried out as a salvage procedure with fairly good results for the patients (due to the intention to treat policy, these results have been used in the statistical analysis).

Another patient suffered from a tenosynovitis of the thumb, which was treated successfully with a cortisone injection.

There was one patient with an entrapment of the dorsal sensory branch of the radial nerve that led to a temporary complex regional pain syndrome type II. This pain syndrome disappeared completely after surgical release of the nerve.

We detected no cases of complex regional pain syndrome type I according to the Veldman and IASP criteria.

One patient has recently died of natural course more than six years after her trapeziometacarpal joint replacement.

\section{DISCUSSION}

In a focused review by Shuler et al. different procedures for surgical intervention in basal joint arthritis of the thumb are extensively described resulting in different outcomes and complication rates [7]. What we can learn from this and the experience from others is that the complication rate for basal joint surgery of the thumb is high for all of these different procedures $[4,6,17]$. Normally the infection rate is low.

There is no evidence-based algorithm that gives us the best treatment for the patient's complaints and the degree of osteoarthritis they suffer from. When we compare tendon position arthroplasty with CMC I arthrodesis, the more favorable procedure remains unclear. The range of motion is supposed to be better after interposition arthroplasty, but on the other hand pinch grip is stronger after arthrodesis [18]. The complication rate Mureau et al. report seems almost unacceptably high for the arthrodesis group (39\%) and gives favor for the lower complication rate of $27 \%$ in the interposition arthroplasty group [19].

Persisting pain is another problem surgeons have to deal with. Either the procedure does not give enough primary pain relief or the resection or ligament reconstruction leads to mechanical painful abutment. Cooney et al. report satisfactory patient outcomes after second surgery with ligament reconstruction in case of failure of primary thumb trapeziometacarpal arthroplasty [20].

The revision rate after silicone implantation reported by Macdermid et al. was 23\% in their series [6]. In our series the revision rate to resection arthroplasty was $10 \%$.

Another complication is sensory loss on the dorsal aspect of the first ray. This may occur because the dorsal sensory branch of the radial nerve or the palmar cutaneous branch of the median nerve are at risk for peroperative traction or iatrogenic laceration, which could lead to a neuroma or complex regional pain syndrome type II (CRPS-II). Loss of sensation on the dorsal aspect of the first ray was reported in $14.5 \%$ by Saehle et al. which means in 8 out of 55 tendon interpositions [4].

Field et al. reported complex regional pain syndrome type $\mathrm{I}$ in $8 \%$ after ligament reconstruction and tendon interposition [21].

Takwale et al. reported even an incidence as high as 19\% of CRPS-I in a special patient category with post-traumatic instability of the trapeziometacarpal joint [17].

In Table 2 we compare our outcome with Torrededia et al. who reported retrospectively about their results after 38 implantations in 34 patients with the same implant we used, the so-called Roseland prosthesis [22]. The difference with their postoperative treatment was that they splinted the first column for one month and started physical therapy one week after surgery. Their complication rate was $18.4 \%$. CRPS type I occurred in 5 patients (13\%). The length of the first column might in their opinion be the cause of CRPS in three of their 5 cases [22].

Table 1. Pre and Postoperative Scores for the Studied Variables

\begin{tabular}{|l|c|c|c|}
\hline & $\begin{array}{c}\text { Mean (SD) } \\
\text { Preop }\end{array}$ & $\begin{array}{c}\text { Mean (SD) } \\
\text { Postop }\end{array}$ & $\begin{array}{c}\text { Difference (95\% CI) } \\
\text { (Postop - Preop) }\end{array}$ \\
\hline \hline First web opening $\left(^{\circ}\right)$ & $59.3(11.0)$ & $74.7(10.6)$ & $15.4(11.0-19.9)$ \\
\hline VAS pain & $7.6(1.2)$ & $1.3(1.7)$ & $-6.2(-5.6--6.9)$ \\
\hline VAS daily activities & $4.1(2.1)$ & $8.6(1.3)$ & $4.5(3.8-5.2)$ \\
\hline VAS satisfaction & $2.2(2.1)$ & $8.7(2.0)$ & 6.000 \\
\hline
\end{tabular}


Table 2. Prevalence of Complex Regional Pain Syndrome CRPS

\begin{tabular}{|c|c|c|}
\hline Vitamin C & No CRPS & CRPS \\
\hline No vitamin $C^{1}$ & 33 & 5 \\
\hline Vitamin $C^{2}$ & 40 & 0 \\
\hline
\end{tabular}

The differences with our study are the early functional treatment we encourage and of course the administration of the vitamin C. The difference in the prevalence of CRPS is significant though (Relative Risk $(\mathrm{RR})=0.87$ (Confidence interval 0.77-0.98), $\mathrm{p}=0.02$ ).

Our patients have a satisfying pain relief and an improved and stable function. Patient satisfaction was strongly associated with the amount of pain reduction (Spearman's rho 0.59). Patients with Dell stage III had logically a longer duration of symptoms before they were operated than patients with Dell stage II.

In general patients should be aware of the high complication and revision rate before they decide to undergo surgery. In case of failure of the procedure or the prosthesis, a salvage procedure can be performed. In such cases we prefer a resection arthroplasty.

\section{CONCLUSION}

The overall complication rate for trapeziometacarpal surgery is high and one of the possible complications is CRPS (variable incidence of 8 to $19 \%$ ) [17, 21]. Torrededia et al. described 5 cases of CRPS after 38 operations (13\%) with the same implant we used, but under vitamin $C$ we detected no CRPS in our study group [22].

Therefore we advise vitamin $\mathrm{C}$ as prophylaxis against CRPS in trapeziometacarpal joint replacement.

\section{REFERENCES}

[1] Van Saase JL, vanRomunde LK, Cats A, Vandenbroucke JP, Valkenburg HA. Epidemiology of osteoarthritis: Zoetermeer survey. Comparison of radiological osteoarthritis in a Dutch population with that in 10 other populations. Ann Rheum Dis 1989; 48: 271-80.

[2] Dell PC, Brushart TM, Smith RJ. Treatment of trapeziometacarpal arthritis: Results of resection arthroplasty. J Hand Surg Am 1978; 3: 243-9.

[3] Eaton RG, Lane LB, Littler JW, Keyser JJ. Ligament reconstruction for the painful thumb carpometacarpal joint: A longterm assessment. J Hand Surg Am 1984; 9: 692-9.
[4] Saehle T, Sande S, Finsen V. Abductor pollicus longus tendon interposition for arthrosis in the first carpometacarpal joint. Acta Orthop Scand 2002; 73: 674-7.

[5] Bamberger HB, Stern PJ, Kiefhaber TR, McDonough JJ, Cantor RM. Trapeziometacarpal joint arthrodesis: A functional evaluation. J Hand Surg Am 1992; 17: 605-11.

[6] MacDermid JC, Roth JH, Rampersaud YR, Bain GI. Trapezial arthroplasty with silicone rubber implantation for advanced osteoarthritis of the trapeziometacarpal joint of the thumb. Can J Surg 2003; 46: 103-10.

[7] Shuler MS, Luria S, Trumble TE. Basal joint arthritis of the thumb. J Am Acad Orthop Surg 2008; 16: 418-23.

[8] Zollinger PE, Tuinebreijer WE, Kreis RW, Breederveld RS. Effect of vitamin $\mathrm{C}$ on frequency of reflex sympathetic dystrophy in wrist fractures: A randomised trial. Lancet 1999; 354: 2025-8.

[9] Zollinger PE, Tuinebreijer WE, Breederveld RS, Kreis RW. Can vitamin $\mathrm{C}$ prevent complex regional pain syndrome in patients with wrist fractures? A randomized, controlled, multicenter doseresponse study. J Bone Joint Surg Am 2007; 89: 1424-31.

[10] Cazeneuve JF, Leborgne JM, Kermad K, Hassan Y. Vitamine C et prévention du syndrome douloureux régional complexe de type 1 après fracture du radius distal traitée chirurgicalement. Acta Orthop Belg 2002; 68: 481-4.

[11] Huskisson EC. Measurement of pain. Lancet 1974; 2: 1127-31.

[12] Moutet F, Lebrun C, Massart P, Sartorius C. The Roseland prosthesis. Chir Main 2001; 20: 79-84.

[13] Veldman PH, Reynen HM, Arntz IE, Goris RJ. Signs and symptoms of reflex sympathetic dystrophy: Prospective study of 829 patients. Lancet 1993; 42: 1012-6.

[14] Merskey H, Bogduk N, Eds. Classification of chronic pain: Descriptions of chronic pain syndromes and definitions of pain terms. Seattle: IASP Press, $2^{\text {nd }} E d, 1994$.

[15] Guidelines Complex Regional Pain Syndrome type I. 2006, Netherlands Society of Rehabilitation Specialists and Netherlands Society of Anesthsiologists. ISBN-10: 90-8523-124-8; ISBN-13: 978-90-8523-124-0.

http://www.posttraumatischedystrofie.nl/pdf/CRPSV்IV்Guidelines. pdf

[16] Zollinger PE. Late reconstruction of a traumatic trapeziometacarpal dislocation with a semi-constrained prosthesis; a case report. Eur J Trauma Emerg Surg 2007; 33: 648-50.

[17] Takwale VJ, Stanley JK, Shahane SA. Post-traumatic instability of the trapeziometacarpal joint of the thumb: diagnosis and the results of reconstruction of the beak ligament. J Bone Joint Surg Br 2004; 86: $541-5$.

[18] Hartigan BJ, Stern PJ, Kiefhaber TR. Thumb carpometacarpal osteoarthritis: Arthrodesis compared with ligament reconstruction and tendon interposition. J Bone Joint Surg Am 2001; 83: 1470-8.

[19] Mureau MA, Rademaker RP, Verhaar JA, Hovius SE. Tendon interposition arthroplasty versus arthrodesis for the treatment of trapeziometacarpal arthritis: A retrospective comparative follow-up study. J Hand Surg Am 2001; 26: 869-76.

[20] Cooney WP III, Leddy TP, Larson DR. Revision of thumb trapeziometacarpal arthroplasty. J Hand Surg Am 2006; 31: 21927.

[21] Field J, Buchanan D. To suspend or not to suspend: A randomized single blind trial of simple trapeziectomy versus trapeziectomy and flexor carpi radialis suspension. J Hand Surg Eur Vol 2007; 32: 462-6.

[22] Torrededia L, Cavanilles-Walker JM, Trigo LE, Matas M, Minoves JMS. Total arthroplasty of the trapeziometacarpal joint with a hydroxyapatite coated (HAC) prosthesis. J Bone Joint Surg Br 2006; 88(Supp 1): 38. 